\title{
Interactions among Low Dose of Methotrexate and Drugs Used in the Treatment of Rheumatoid Arthritis
}

\author{
Marinella Patanè, ${ }^{1,2}$ Miriam Ciriaco, ${ }^{1,2}$ Serafina Chimirri, ${ }^{1,2}$ \\ Francesco Ursini, ${ }^{3}$ Saverio Naty, ${ }^{3}$ Rosa Daniela Grembiale, ${ }^{3}$ Luca Gallelli, ${ }^{1,2}$ \\ Giovambattista De Sarro, ${ }^{1,2}$ and Emilio Russo ${ }^{1,2}$ \\ ${ }^{1}$ Department of Health Science, School of Medicine, University of Catanzaro, Viale Europa, \\ 88100 Catanzaro, Italy \\ ${ }^{2}$ Pharmacovigilance's Center Regione Calabria, University Hospital Mater Domini, 88100 Catanzaro, Italy \\ ${ }^{3}$ Rheumatology Research Unit and Ph.D. Program in Molecular Oncology, Experimental Immunology and \\ Development of Innovative Therapies, University of Catanzaro, 88100 Catanzaro, Italy
}

Correspondence should be addressed to Luca Gallelli; gallelli@unicz.it

Received 17 March 2013; Revised 9 April 2013; Accepted 16 April 2013

Academic Editor: Raymond M. Quock

Copyright (C) 2013 Marinella Patanè et al. This is an open access article distributed under the Creative Commons Attribution License, which permits unrestricted use, distribution, and reproduction in any medium, provided the original work is properly cited.

Methotrexate (MTX) is a nonbiological disease-modifying antirheumatic drug that has shown both a good control of clinical disease and a good safety. Usually drug-drug interactions (DDIs) represent the most limiting factor during the clinical management of any disease, in particular when several drugs are coadministered to treat the same disease. In this paper, we report the interactions among MTX and the other drugs commonly used in the management of rheumatoid arthritis. Using Medline, PubMed, Embase, Cochrane libraries, and Reference lists, we searched for the articles published until June 30, 2012, and we reported the most common DDIs between MTX and antirheumatic drugs. In particular, clinically relevant DDIs have been described during the treatment with MTX and NSAIDs, for example, diclofenac, indomethacin, or COX-2 inhibitors, and between MTX and prednisone or immunosuppressant drugs (e.g., leflunomide and cyclosporine). Finally, an increase in the risk of infections has been recorded during the combination treatment with MTX plus antitumor necrosis factor- $\alpha$ agents. In conclusion, during the treatment with MTX, DDIs play an important role in both the development of ADRs and therapeutic failure.

\section{Introduction}

Rheumatoid arthritis (RA) is a chronic and autoimmune disease affecting about $1 \%$ of people, with the highest incidence between 40 and 70 years [1]. Drugs able to reduce inflammation and cells activation may be used in the management of RA. In particular, nonsteroidal anti-inflammatory drugs (NSAIDs) as well as immunosuppressive agents (i.e., glucocorticoids), disease-modifying antirheumatic drugs (DMARDs), and agents that are able to block the proinflammatory cytokine tumor necrosis factor- $\alpha$ (anti-TNF- $\alpha$ ) may be used (Table 1).

NSAIDs, acting on cyclooxygenases, are able to control the inflammation and the clinical symptoms [2-4], but not the disease's progression; their use as monotherapy for a long time is limited for the development of adverse drug reactions (ADRs) [5].

Glucocorticoids (e.g., dexamethasone and prednisone) are anti-inflammatory and immune suppressor agents that are able to reduce the inflammation and the progression of RA, through the inhibition of cytokines secretion and osteoclasts activation [6-15].

However, even if they represent a first-line treatment in patients with RA, their use is limited for the development of serious ADRs such as loss of bone mass, increased risk of fractures, infections, diabetes and hypertension [16-18]. The DMARDs group, includes both nonbiological and biological drugs; between the DMARDs, methotrexate (MTX) due to 
TABLE 1: Drugs used in the management of rheumatoid arthritis.

\begin{tabular}{|c|c|c|c|}
\hline \multicolumn{2}{|c|}{ Drugs for symptomatic control } & \multicolumn{2}{|l|}{ DMARDs } \\
\hline NSAID & Corticosteroids & Nonbiological & Biological \\
\hline $\begin{array}{l}\text { Celecoxib } \\
\text { Etoricoxib } \\
\text { Lumiracoxib } \\
\text { Parecoxib }\end{array}$ & Prednisone & $\begin{array}{l}\text { Azathioprine } \\
\text { Ciclosporin [hydroxy]-chloroquine } \\
\text { Leflunomide } \\
\text { Methotrexate } \\
\text { Sulphasalazine }\end{array}$ & $\begin{array}{l}\text { Anti-TNF- } \alpha \text { agents: infliximab, adalimumab, } \\
\text { etanercept, golimumab, and certolizumab pegol } \\
\text { Anti-IL1: anakinra } \\
\text { Anti-IL-6: tocilizumab } \\
\text { Anti-CD20: rituximab } \\
\text { Anti-CD80/86-CD28: abatacept }\end{array}$ \\
\hline
\end{tabular}

TABLE 2: Disease-modifying antirheumatic drugs.

\begin{tabular}{|c|c|c|c|c|}
\hline Drug & Use & Dosage & Adverse effects & Mechanism \\
\hline Abatacept & $\begin{array}{l}\text { Monotherapy in } \\
\text { moderate severe RA or } \\
\text { with DMARDs }\end{array}$ & $\begin{array}{l}500 / 1000 \mathrm{mg} \text { iv for } 2 \\
\text { weeks then for } 4 \\
\text { weeks }\end{array}$ & $\begin{array}{l}\text { Headache, blood hypertension, nausea, } \\
\text { infections respiratory system, vertigo, and } \\
\text { severe infection }\end{array}$ & $\begin{array}{l}\text { Modulator of } \\
\text { T-lymphocyte } \\
\text { activation }\end{array}$ \\
\hline Adalimumab & Moderate or severe AR & $40 \mathrm{mg} \mathrm{sc}$. for 2 weeks & $\begin{array}{l}\text { Myositis, headache, rash, nausea, blood } \\
\text { hypertension, hyperlipidemia, and higher } \\
\text { plasma transaminases levels }\end{array}$ & Anti-TNF- $\alpha$ \\
\hline Anakinra & $\begin{array}{l}\text { Monotherapy in } \\
\text { moderate/severe RA in } \\
\text { patient with } \geq 1 \text { DMARD } \\
\text { not efficacy }\end{array}$ & $100 \mathrm{mg} /$ die sc. & $\begin{array}{l}\text { Abdominal pain, diarrhea, headache, } \\
\text { fever, and infections of respiratory system }\end{array}$ & Anti-IL-1 \\
\hline Certolizumab & Moderate or severe AR & $\begin{array}{l}400 \mathrm{mg} \text { sc. for } 2 \text { weeks } \\
\text { then } 200 \mathrm{mg} \text { for } 2 \\
\text { weeks }\end{array}$ & $\begin{array}{l}\text { Rash, headache, blood hypertension, } \\
\text { fever, and asthenia }\end{array}$ & Anti-TNF- $\alpha$ \\
\hline Etanercept & $\begin{array}{l}\text { Moderate or severe AR } \\
\text { with DMARD }\end{array}$ & $50 \mathrm{mg} /$ weeks sc. & $\begin{array}{l}\text { Pain into injection site, infections, } \\
\text { headache, rash, vertigo, and asthenia }\end{array}$ & Anti-TNF- $\alpha$ \\
\hline Golimumab & RA M/S with MTX & $50 \mathrm{mg} / \mathrm{month} \mathrm{sc}$. & $\begin{array}{l}\text { Blood hypertension, higher plasma } \\
\text { transaminases levels, and } \\
\text { vertigo, rhinitis }\end{array}$ & Anti-TNF- $\alpha$ \\
\hline Infliximab & $\begin{array}{l}\text { Moderate or severe AR } \\
\text { with MTX }\end{array}$ & $\begin{array}{l}3 \mathrm{mg} / \mathrm{kg} \text { iv one time } \\
\text { then on } 2 \text { and } 6 \text { weeks }\end{array}$ & $\begin{array}{l}\text { Fever, headache, rash, myalgia, asthenia, } \\
\text { dyspnea, and higher plasma } \\
\text { transaminases levels }\end{array}$ & Anti-TNF- $\alpha$ \\
\hline Rituximab & $\begin{array}{l}\text { Moderate or severe AR, } \\
\text { with MTX in patient and } \\
\text { without response to } \geq 1 \\
\text { anti-TNF- } \alpha \text { agent }\end{array}$ & $\begin{array}{l}1000 \mathrm{mg} \text { iv in days } 1 \\
\text { and } 15 \text { then at } 24 \\
\text { weeks }\end{array}$ & $\begin{array}{l}\text { Fever, nausea, hypotension, itching, and } \\
\text { myelosuppression }\end{array}$ & $\begin{array}{l}\text { Modulator of } \\
\text { B-cell activation }\end{array}$ \\
\hline
\end{tabular}

its good safety and clinical efficacy, represents the first choice for the treatment of RA [19]. When a 6-month treatment with conventional drugs (NSAIDs, glucocorticoid, and DMARDs) is ineffective or when RA is severe (e.g., early destruction or unfavorable prognosis), the treatment with biological DMARDs may be started. A combination treatment between MTX and glucocorticoids or biological drugs is also often considered (Table 2) [20-22]. In patients with RA, the Food and Drug Administration (FDA) approved the use of antiTNF- $\alpha$ (infliximab, adalimumab, golimumab, certolizumab, pegol, and etanercept) as combined therapies [23]. Previously, we documented that a multidrug treatment may be related to a higher development of ADRs and/or drug-drug interactions (DDIs) [24-42], and this represents a major issue during the clinical management of any disease requiring polytherapy. Based on this background, the aim of the present review is to describe the DDIs between MTX and the other drugs used in the treatment of patients with RA.

\section{Methods}

The Medline, PubMed, Embase, and Cochrane library databases were searched for articles published until June 30, 2012. Secondary search included articles cited in reference lists identified by the primary search. Records were first screened by title/abstract before full text articles were retrieved for eligibility evaluation. Remaining articles were then subjected to a citation search before a final hand search of all reference lists. Papers were deemed eligible if they included any form of words: "rheumatoid arthritis," "antirheumatic drugs," "NSAIDs," "glucocorticoids," "DMARDs," "biologic drugs," and "drug-drug interaction." All citations were downloaded into Endnote software version 14, and duplicates were deleted. MP, MC, and FU screened all articles by title/abstract to determine their eligibility, and LG reviewed a random sample of $15 \%$ in order to evaluate the reliability of the selection process. In order to avoid a bias 


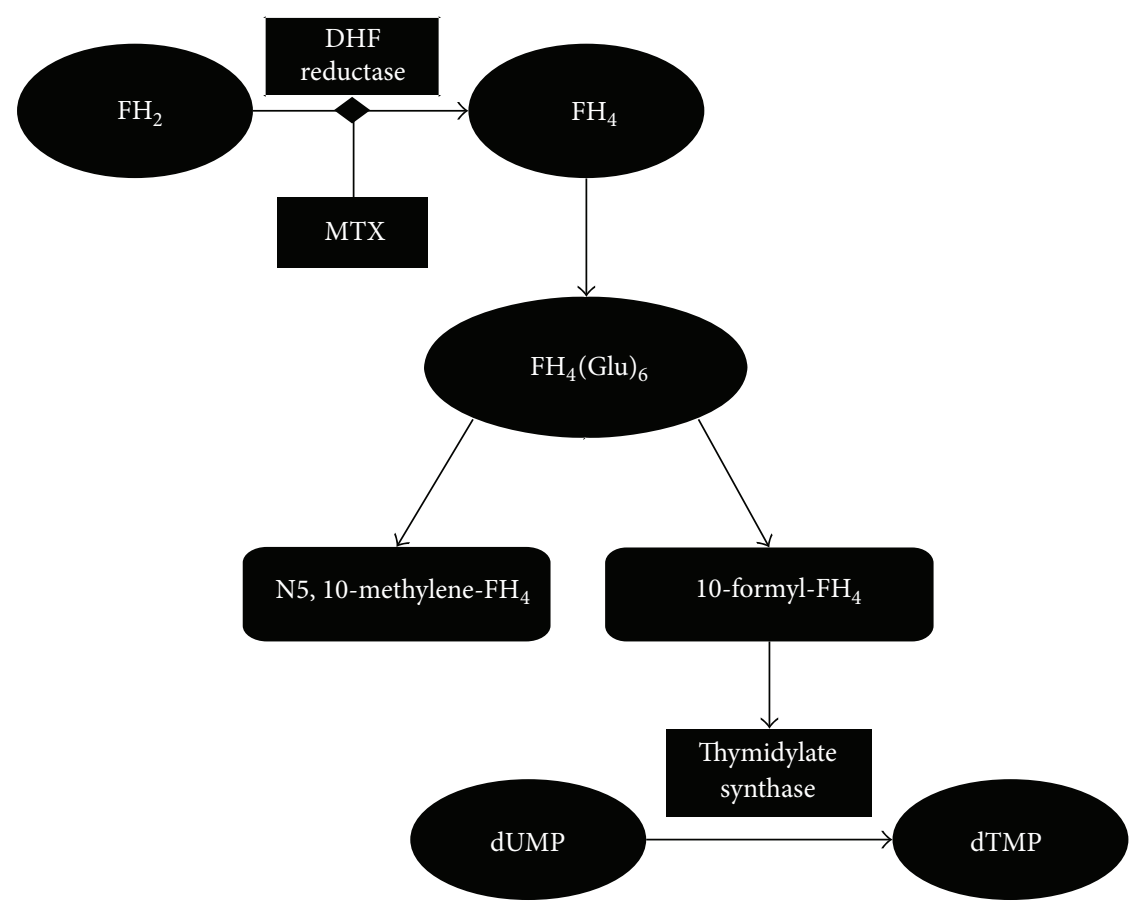

FIGURE 1: Schematic representation of methotrexate's pharmacodynamic. Methotrexate (MTX) indirectly blocks the formation of dTMP by inhibiting DHF reductase. $\mathrm{FH}_{2}$, which accumulates following the inhibition of DHF reductase, in turn inhibits thymidylate synthase. DHF = dihydrofolate; $\mathrm{FH}_{2}=$ dihydrofolic acid $\mathrm{FH}_{4}=$ tetrahydrofolic acid; dTMP = thymidine monophosphate; and dUMP = deoxyuridine monophosphate.

of exclusion, the full text articles were retrieved following first round exclusions and were also subjected to two independent eligibility reviews (MP 100\% and LG 15\%), this time with perfect agreement. The studies evaluated as eligible were enclosed in the present review.

\section{Methotrexate Pharmacology}

3.1. Pharmacokinetic. After oral administration, MTX is rapidly adsorbed, with a Tmax of 2 hours and a terminal halflife of 8-10 hours. In plasma, MTX binds reversibly to albumin (60-70\%) and rapidly accumulates inside red blood cells through the reduced folate carrier. In red cells, MTX receives 2-5 glutamate moieties and is retained as MTX polyglutamates (MTXGlu) [43, 44]. The enzyme gamma-glutamyl hydrolase removes the terminal glutamate molecules; therefore, MTX returns to its monoglutamate form and can be transported out of the red cells by multidrug-resistant protein [43]. MTX is predominantly eliminated as an unmodified drug by the kidney (80\%) via the human organic anion transporter-3 (HTO-3) in the renal proximal tubule.

3.2. Pharmacodynamic. MTX is an "antimetabolite" that is able to block the chain elongation of DNA leading to the arrest of cell cycle. Folic acid analogues, competitively and reversibly inhibit the enzyme dihydrofolate reductase (DHF reductase) that catalyzes the transformation of dihydrofolic acid $\left(\mathrm{FH}_{2}\right)$ into tetrahydrofolic acid $\left(\mathrm{FH}_{4}\right)$ (Figure 1$)$.

$\mathrm{FH}_{4}$, inside the cells, undergoes the addition of 6 glutamic-acid residues, by the enzyme folic-glutamate synthase to obtain $\mathrm{FH}_{4}(\mathrm{Glu})_{6}$. Then, it is transformed into two molecules: $\mathrm{N} 5,10$-methenyl- $\mathrm{FH}_{4}$ and 10-formyl- $\mathrm{FH}_{4}$ (Figure 1).

N5,10-methenyl- $\mathrm{FH}_{4}$ acts as a donor of monocarboniose units in the reaction that forms thymidine monophosphate (dTMP) from deoxyuridine monophosphate (dUMP); this reaction is catalyzed by the enzyme thymidylate synthase.

Thymidine is required for the synthesis of DNA and RNA. MTX indirectly blocks the formation of dTMP by inhibiting DHF reductase. Furthermore, $\mathrm{FH}_{2}$, which accumulates following the inhibition of DHF reductase, in turn inhibits thymidylate synthase (Figure 1). Through this mechanism, MTX blocks the synthesis of DNA and RNA and acts as an antimetabolite, mainly during the S-phase of cell cycle, by presenting a greater cytotoxic effect in cells with high turnover, for example, cancer cells [22]. Moreover, it has been also reported that MTX is able to inhibit the production of cytokines (e.g., IL-1), leukotriene B4, and histamine $[45,46]$.

In this light, MTX is used to treat patients with hematological malignancies as well as patients with rheumatoid arthritis, juvenile rheumatoid arthritis, and skin disorders (e.g., psoriasis, dermatomyositis, systemic sclerosis, morphoea, cutaneous sarcoidosis, and different types of eczema).

\section{Methotrexate's Interactions with Drugs Commonly Used in RA Treatment}

DDIs represent the commonest causes of ADRs, particularly in the elderly and can be classified into two main groups pharmacokinetic or pharmacodynamic [52]. 
TABLE 3: DDIs between MTX and NSAIDs.

\begin{tabular}{lcc}
\hline Drug & Mechanism & Effects \\
\hline $\begin{array}{l}\text { NSAIDs (indomethacin, ketoprofen, } \\
\text { naproxen, and diclofenac) }\end{array}$ & $\begin{array}{c}\text { Competition for } \\
\text { tubular secretion via } \\
\text { the HOAT-3 }\end{array}$ & $\begin{array}{c}\text { NSAIDs decrease the excretion of } \\
\text { MTX with an increase in ADRs. }\end{array}$ \\
$\begin{array}{l}\text { COX-2 inhibitors Etoricoxib } \\
\text { Inhibition of HOAT-3 }\end{array}$ & $\begin{array}{c}\text { Decreased excretion of MTX } \\
\text { with an increase in ADRs }\end{array}$ \\
$\begin{array}{l}\text { Other COX-2 inhibitors (i.e., celecoxib } \\
\text { and lumiracoxib) }\end{array}$ & & No data \\
\hline
\end{tabular}

4.1. MTX and NSAIDS. A recent Cochrane systematic review by Colebatch and coworkers [53] evaluating 8621 studies documented that only 17 publications reported a concurrent use of MTX and NSAID, but none reported ADRs on lung, liver, or renal function and no increase in MTX withdrawal or in other major toxicity. On the other hand, a pharmacokinetic DDIs, on HOAT-3, has been described during the treatment with MTX plus NSAIDs, particularly with ketoprofen, indomethacin, naproxen, and diclofenac [47, 48]. Moreover, an experimental study has recently documented that etoricoxib is able to inhibit the HOAT-3 in a competitive and dose-dependent manner [49]; therefore, DDI could be hypothesized during the treatment with MTX.

In contrast, up to date no data have been published concerning a DDI between celecoxib and MTX $[50,51]$ (Table 3).

4.2. MTX and Glucocorticoids. An experimental study demonstrated that an oral pretreatment with dexamethasone reduces up to $53 \%$ of the biliary clearance of MTX, inducing a hepatocellular impairment [65].

Although liver toxicity has been reported in children with brain tumor treated with MTX and dexamethasone [66], definitive data have not been published concerning possible DDIs between MTX and glucocorticoids.

In agreement, Malysheva et al. [67] failed to report the development of DDIs during the concomitant treatment with MTX plus prednisolone.

4.3. MTX and DMARDs. The combination of MTX and either leflunomide or sulphasalazine in nonresponders RA patients reduced pain symptoms but induced an increase in serious ADRs. In particular, since pharmacokinetic DDIs were not reported in patients treated with MTX (mean dose $17.2 \mathrm{mg}$ per week) plus leflunomide (100 mg daily for 2 days as a loading dose followed by 10 to $20 \mathrm{mg}$ daily) [68], several papers reported an increase in both liver toxicity and blood dyscrasia (i.e., pancytopenia) (Table 4). In this light, the UK manufacturer suggests that the coadministration of MTX and leflunomide is not advisable [54-59]. In agreement Lee et al. [60] reported an increased risk of liver fibrosis in patients with RA treated with leflunomide plus methotrexate. However, the Smile study evaluating 2975 patients with RA, recently documented the safety of the association between MTX and leflunomide [69]. In contrast, Katchamart et al. [61] evaluating 19 clinical trials (2025 patients) documented that the concurrent treatment with MTX plus sulphasalazine
TABLE 4: MTX's interaction with DMARDs and immunosuppressant.

\begin{tabular}{lcc}
\hline Drug & Effects & References \\
\hline $\begin{array}{l}\text { Leflunomide and } \\
\text { sulphasalazine }\end{array}$ & $\begin{array}{c}\text { Increase in liver and } \\
\text { blood toxicity } \\
\text { Contrasting data }\end{array}$ & {$[54-62]$} \\
Cyclosporine & Renal toxicity & {$[63]$} \\
& No interactions & {$[64]$} \\
Mycophenolate mofetil & No data & \\
\hline
\end{tabular}

is correlated with an increase in both liver and gastrointestinal toxicity (Table 4). Finally, even if sulphasalazine displaces MTX from its plasmatic albumin site, no net change in free MTX concentration or an increased risk of toxicity was underlined. This is probably due to the percentage (50\%) of binding and the increased displacement would likely lead to an increased elimination sulphasalazine is a HOAT-1 and HOAT-3 inhibitors; therefore, it is able to inhibit the renal excretion of MTX [62]. However, the clinical impact of this DDI should be better investigated in clinical trials.

4.4. MTX and Immunosuppressant. Usually, cyclosporine administered as monotherapy can induce kidney toxicity, so it should be started at lower dose (Table 4). It was previously suggested that combined treatment with cyclosporine and other antirheumatic drugs, such as MTX, is very promising [78]. However, an open-label pharmacokinetic study published by Baraldo et al. [79] documented in 26 RA patients treated for 14 days with MTX (7.5 to $22.5 \mathrm{mg}$ weekly) plus cyclosporine $(1.5 \mathrm{mg} / \mathrm{kg}$ bid) a significant increase $(P<0.01)$ in mean area under the curve (AUC) of MTX (26\%), with a significant decrease $(80 \% ; P<0.001)$ of its active metabolite (7-hydroxymethotrexate). This DDI is related to a lower activity and a higher toxicity. In agreement, more recently, another study reported an increase in kidney ADRs (e.g., hypertension or increase in serum creatinine) in RA patients treated with cyclosporine plus MTX in comparison to patients receiving cyclosporine alone [63]. In contrast, Sarzi-Puttini et al. [64] did not show any increase in ADRs in patients treated with cyclosporine $(3 \mathrm{mg} / \mathrm{kg})+$ MTX (from 7.5 to $10 \mathrm{mg}$ weekly) in respect to patients treated with cyclosporine alone. At the moment, no DDIs during the treatment with MTX + mycophenolate mofetil have been reported; therefore, this coadministration seems to be well tolerated (Table 4 ). 
TABLE 5: DDIs between MTX's and biological drugs.

\begin{tabular}{lcc}
\hline Drug & Effects & References \\
\hline $\begin{array}{l}\text { Infliximab, adalimumab, } \\
\text { golimumab, and } \\
\text { certolizumab pegol }\end{array}$ & $\begin{array}{c}\text { Increased risk of } \\
\text { infections }\end{array}$ & {$[70-72]$} \\
$\begin{array}{l}\text { Etanercept } \\
\text { Adalimumab }\end{array}$ & No DDIs & {$[72]$} \\
$\begin{array}{l}\text { Tocilizumab, certolizumab pegol, } \\
\text { and golimumab }\end{array}$ & No DDIs & {$[73]$} \\
Abatacept & No DDIs & {$[74-76]$} \\
\hline
\end{tabular}

4.5. MTX and Biological Drugs. The cotreatment with antiTNF- $\alpha$ plus MTX induces synergistic effects on the immunosuppressive activity of MTX, even if this treatment may be related to an increased risk of infections [70-72]. However, no pharmacokinetic DDIs were documented during the treatment with etanercept (subcutaneous dose) plus MTX (oral dose) [72].

Similarly, several clinical trials performed in patients with active RA without an adequate response to MTX; the addition of adalimumab to MTX achieved an improvement of RA symptoms, without the development of pharmacokinetic DDIs [73, 80, 81].

However, this treatment may be related to an increase in liver enzymes; therefore, it is prudent to increase the frequency of liver enzyme monitoring in patients receiving this cotreatment. Other data documented the absence of pharmacokinetic DDIs during the contemporary administration of MTX plus rituximab [82], tocilizumab [74], certolizumab pegol [75], or golimumab [76] (Table 5).

Abatacept, a modulator of T-lymphocyte activation, approved for the treatment of active RA, has been recommended for nonresponder patients to DMARDs such as MTX or anti-TNF- $\alpha$ [77]. A recent Cochrane review demonstrated significant lower risk of serious ADRs during the treatment with abatacept in respect to other biological drugs [83]. Since an interaction between this drug and MTX has not been established, the ACR recommend the coadministration of abatacept and MTX; abatacept in monotherapy is not recommended due to the lack of data.

\section{Discussion and Conclusion}

The depletion of folate and the inability of the cells to synthesize DNA at the same time can explain the antineoplastic/antirheumatic effects possessed by MTX and also its toxicity. The suppressive effect of MTX on hematopoietic system and the risk of fibrosis, cirrhosis, or gastrointestinal ulcer require a frequent monitoring of functional parameters. The supplementation of folic acid is helpful to reduce the MTX's toxicity [84]. The importance of pharmacovigilance studies in patients treated with MTX is also related to risk of DDIs that may increase the MTX's toxicity. After absorption, MTX is bounded to the serum albumin for its distribution and therefore can be displaced by other drugs that are coadministered. The kidney clearance of MTX may be reduced by NSAIDs or DMARDs, while the risk of liver toxicity and bone marrow suppression is increased during the treatment with drugs with similar ADRs $[84,85]$. In conclusion, during the treatment with MTX, it is necessary to keep in consideration the risk of DDIs that are able to increase the risk of hepatotoxicity, nephrotoxicity, myelotoxicity, and other toxic effects.

\section{Summary}

(i) DDIs are very important and must be timely recognized in order to prevent the development of ADRs or therapeutic failure.

(ii) Low dose of MTX represents a safe treatment for patients with RA receiving other treatments with antirheumatic drugs, since some DDIs may occur.

(iii) The association MTX + NSAIDs or etoricoxib may be related to an increase of MTX toxicity.

(iv) The association MTX + leflunomide or MTX + sulphasalazine may induce liver toxicity and/or blood toxicity.

(v) Very few data have been published regarding the association between MTX and biological DMARDs.

(vi) In order to prevent the development of DDIs, it is important to decrease the dosage of MTX or of the drugs that are coadministered.

(vii) In the presence of ADRs during the treatment, it is useful to evaluate the plasma concentration of the drugs.

\section{Conflict of Interests}

The authors have no conflict of interests to be declared.

\section{Acknowledgments}

Funds needed to purchase articles for this survey were granted by "Rete Regionale di informazione sul farmaco: informazione, formazione, e farmacovigilanza" Project Sponsored by Regione Calabria on the Behalf of Agenzia Italiana del Farmaco (AIFA).

\section{References}

[1] S. Tambar and E. M. Ruderman, "Current management of rheumatoid arthritis," Managed Care Interface, vol. 20, no. 7, pp. 18-24, 2007.

[2] S. De Fazio, L. Gallelli, P. Gareri, D. Mazzotta, P. A. Rende, and G. De Sarro, "Pharmacological properties of nonsteroideal antiinflammatory drugs: a review," Current Topics in Pharmacology, vol. 13, no. 1, pp. 75-83, 2009.

[3] L. Gallelli, O. Galasso, A. Urzino et al., "Characteristics and clinical implications of the pharmacokinetic profile of ibuprofen in patients with knee osteoarthritis," Clinical Drug Investigation, vol. 32, pp. 827-833, 2012. 
[4] F. Oliva and L. Gallelli, "Ibuprofen pharmacology and its implications for musculoskeletal disorders," Functional Neurology, vol. 25, no. 3, supplement 1, pp. 1-19, 2010.

[5] L. Gallelli, M. Colosimo, D. Pirritano et al., "Retrospective evaluation of adverse drug reactions induced by nonsteroidal anti-inflammatory drugs," Clinical Drug Investigation, vol. 27, no. 2, pp. 115-122, 2007.

[6] J. W. Bijlsma, "Disease control with glucocorticoid therapy in rheumatoid arthritis," Rheumatology, vol. 51, supplement 4, pp. 9-13, 2012.

[7] M. Boers, "Prednisone for rheumatoid arthritis: the detriment of the doubt," Nederlands Tijdschrift voor Geneeskunde, vol. 155, no. 32, p. A5069, 2012.

[8] L. Clarke and J. Kirwan, "Efficacy, safety and mechanism of action of modified-release prednisone in rheumatoid arthritis," Therapeutic Advances in Musculoskeletal Disease, vol. 4, no. 3, pp. 159-166, 2012.

[9] G. Haugeberg, A. Strand, T. K. Kvien, and J. R. Kirwan, "Reduced loss of hand bone density with prednisolone in early rheumatoid arthritis: results from a randomized placebocontrolled trial," Archives of Internal Medicine, vol. 165, no. 11, pp. 1293-1297, 2005.

[10] D. Makrygiannakis, S. Revu, M. Engstrom et al., "Local administration of glucocorticoids decreases synovial citrullination in rheumatoid arthritis," Arthritis Research \& Therapy, vol. 14, no. 1, p. R20, 2012.

[11] E. McKeown, V. P. Bykerk, F. De Leon et al., "CATCH Investigators. Quality assurance study of the use of preventative therapies in glucocorticoid-induced osteoporosis in early inflammatory arthritis: results from the CATCH cohort," Rheumatology, vol. 51, no. 9, pp. 1662-1669, 2012.

[12] C. Montecucco, M. Todoerti, G. Sakellariou, C. A. Scirè, and R. Caporali, "Low-dose oral prednisone improves clinical and ultrasonographic remission rates in early rheumatoid arthritis: results of a 12-month open-label randomised study," Arthritis Research \& Therapy, vol. 14, no. 3, p. R112, 2012.

[13] J. R. O'Dell, “Therapeutic strategies for rheumatoid arthritis," The New England Journal of Medicine, vol. 350, no. 25, pp. 25912630, 2004.

[14] R. A. Quax, J. W. Koper, P. H. de Jong et al., "In vitro glucocorticoid sensitivity is associated with clinical glucocorticoid therapy outcome in rheumatoid arthritis," Arthritis Research \& Therapy, vol. 14, no. 4, p. R195, 2012.

[15] D. L. Scott, K. Pugner, K. Kaarela et al., "The links between joint damage and disability in rheumatoid arthritis," Rheumatology, vol. 39, no. 2, pp. 122-132, 2000.

[16] U. Baschant, N. E. Lane, and J. Tuckermann, "The multiple facets of glucocorticoid action in rheumatoid arthritis," Nature Reviews Rheumatology, vol. 8, no. 11, pp. 645-655, 2012.

[17] S.-G. Lee, Y.-E. Park, S.-H. Park et al., "Increased frequency of osteoporosis and BMD below the expected range for age among South Korean women with rheumatoid arthritis," International Journal of Rheumatic Diseases, vol. 15, no. 3, pp. 289-296, 2012.

[18] J. R. Curtis, A. Lanas, A. John, D. A. Johnson, and K. L. Schulman, "Factors associated with gastrointestinal perforation in a cohort of patients with rheumatoid arthritis," Arthritis Care \& Research, vol. 64, no. 12, pp. 1819-1828, 2012.

[19] J. Zeidler, H. Zeidler, and J. M. Graf von der Schulenburg, "Therapy of rheumatoid arthritis with methotrexate : claims data analysis of treatment patterns," Zeitschrift für Rheumatologie, vol. 71, no. 10, pp. 900-907, 2012.
[20] K. Kruger, J. Wollenhaupt, K. Albrecht et al., "guidelines for the sequential medical treatment of rheumatoid arthritis. Adapted EULAR recommendations and updated treatment algorithm," Zeitschrift für Rheumatologie, vol. 71, no. 7, pp. 592-603, 2012.

[21] A. D. Protogerou, E. Zampeli, and P. P. Sfikakis, "Low-dose prednisone inclusion in a methotrexate-based, tight control strategy for early rheumatoid arthritis," Annals of Internal Medicine, vol. 157, no. 4, pp. 299-300, 2012.

[22] S. K. Agarwal, "Biologic agents in rheumatoid arthritis: an update for managed care professionals," Journal of Managed Care Pharmacy, vol. 179, supplement B, pp. S14-S18, 2011.

[23] K. G. Saag, G. T. Gim, N. M. Patkar et al., "American College of Rheumatology 2008 recommendations for the use of nonbiologic and biologic disease-modifying antirheumatic drugs in rheumatoid arthritis," Arthritis Care and Research, vol. 59, no. 6, pp. 762-784, 2008.

[24] L. Gallelli, G. Ferreri, M. Colosimo et al., "Adverse drug reactions to antibiotics observed in two pulmonology divisions of Catanzaro, Italy: a six-year retrospective study," Pharmacological Research, vol. 46, no. 5, pp. 395-400, 2002.

[25] L. Gallelli, G. Ferreri, M. Colosimo et al., "Retrospective analysis of adverse drug reactions to bronchodilators observed in two pulmonary divisions of Catanzaro, Italy," Pharmacological Research, vol. 47, no. 6, pp. 493-499, 2003.

[26] L. Gallelli, V. Guadagnino, B. Caroleo, N. Marigliano, G. B. De Sarro, and A. Izzi, "Bilateral skin ulceration after injection of pegylated interferon- $\alpha-2 \mathrm{~b}$ in a patient with chronic hepatitis C," Clinical Drug Investigation, vol. 23, no. 9, pp. 615-619, 2003.

[27] L. Gallelli, M. Nardi, T. Prantera et al., "Retrospective analysis of adverse drug reactions induced by gemcitabine treatment in patients with non-small cell lung cancer," Pharmacological Research, vol. 49, no. 3, pp. 259-263, 2004.

[28] L. Gallelli, V. Guadagnino, B. Caroleo, N. Marigliano, and G. De Sarro, "Cutaneous ulceration induced by interferon alfa," Annals of Pharmacotherapy, vol. 38, no. 1, pp. 173-174, 2004.

[29] L. Gallelli, S. Del Negro, S. Naty, M. Colosimo, R. Maselli, and G. De Sarro, "Levofloxacin-induced taste perversion, blurred vision and dyspnoea in a young woman," Clinical Drug Investigation, vol. 24, no. 8, pp. 487-489, 2004.

[30] P. Gareri, L. Gallelli, G. Ferreri Ibbadu, R. Lacava, E. Russo, and G. De Sarro, "Melaena following use of the cholinesterase inhibitor rivastigmine," Clinical Drug Investigation, vol. 25, no. 3, pp. 215-217, 2005.

[31] L. Gallelli, M. Ferraro, G. F. Mauro, and G. De Sarro, "Generalised dermatitis induced by pegylated interferon- $\alpha-2 b$ in a patient infected with genotype-1 hepatitis $C$ virus: presentation of a case," Clinical Drug Investigation, vol. 25, no. 4, pp. 281-284, 2005.

[32] L. Gallelli, M. Ferraro, G. F. Mauro, S. De Fazio, and G. De Sarro, "Nimesulide-induced hepatotoxicity in a previously healthy woman," Clinical Drug Investigation, vol. 25, no. 6, pp. 421-424, 2005.

[33] L. Gallelli, A. Gallelli, G. Vero et al., "Acute renal failure probably induced by prulifloxacin in an elderly woman: a first case report," Clinical Drug Investigation, vol. 26, no. 1, pp. 49-53, 2006.

[34] L. Gallelli, S. De Fazio, E. Corace, C. De Sarro, C. S. Garcia, and P. De Fazio, "Generalised urticaria in a young woman treated with clomipramine and after ingestion of codfish: a case report," Pharmacopsychiatry, vol. 39, no. 4, pp. 154-156, 2006.

[35] A. Siniscalchi, L. Gallelli, and G. De Sarro, "Combined topiramate and declorazepam therapy in a patient affected by essential 
tremor," Parkinsonism and Related Disorders, vol. 13, no. 2, pp. 129-130, 2007.

[36] P. Gareri, P. De Fazio, A. Cotroneo et al., "Anticholinergic druginduced delirium in an elderly alzheimer's dementia patient," Archives of Gerontology and Geriatrics, vol. 44, pp. 199-206, 2007.

[37] A. Siniscalchi, L. Gallelli, S. De Fazio, and G. De Sarro, "Psychic disturbances associated with sodium valproate plus levetiracetam," Annals of Pharmacotherapy, vol. 41, no. 3, pp. 527-528, 2007.

[38] P. Gareri, P. De Fazio, L. Gallelli et al., "Venlafaxine-propafenone interaction resulting in hallucinations and psychomotor agitation," Annals of Pharmacotherapy, vol. 42, no. 3, pp. 434-438, 2008.

[39] L. Gallelli, O. Staltari, C. Palleria, G. De Sarro, and M. Ferraro, "Hepatotoxicity induced by methimazole in a previously health patient," Current Drug Safety, vol. 4, no. 3, pp. 204-206, 2009.

[40] A. Siniscalchi, L. Gallelli, G. Calabrò, G. A. Tolotta, and G. De Sarro, "Phenobarbital/lamotrigine coadministrationinduced blood dyscrasia in a patient with epilepsy," Annals of Pharmacotherapy, vol. 44, no. 12, pp. 2031-2034, 2010.

[41] G. Di Mizio, L. Gallelli, V. Barbieri et al., "Capecitabine-induced, rapid decrease of renal function due to drug dispensing error in a hospital pharmacy," Journal of Clinical Pharmacology, vol. 51, no. 1, pp. 117-119, 2011.

[42] F. Scicchitano, C. Giofrè, C. Palleria et al., "Pharmacovigilance and drug safety 2011 in Calabria (Italy): adverse events analysis," Journal of Research in Medical Sciences, vol. 17, no. 9, pp. 872$875,2012$.

[43] J. M. Dalrymple, L. K. Stamp, J. L. O’Donnell, P. T. Chapman, M. Zhang, and M. L. Barclay, "Pharmacokinetics of oral methotrexate in patients with rheumatoid arthritis," Arthritis and Rheumatism, vol. 58, no. 11, pp. 3299-3308, 2008.

[44] P. Seideman, O. Beck, S. Eksborg, and M. Wennberg, "The pharmacokinetics of methotrexate and its 7-hydroxy metabolite in patients with rheumatoid arthritis," British Journal of Clinical Pharmacology, vol. 35, no. 4, pp. 409-412, 1993.

[45] R. Segal, E. Mozes, M. Yaron, and B. Tartakovsky, “The effects of methotrexate on the production and activity of interleukin-1," Arthritis and Rheumatism, vol. 32, no. 4, pp. 370-377, 1989.

[46] R. Segal, M. Yaron, and B. Tartakovsky, "Methotrexate: mechanism of action in rheumatoid arthritis," Seminars in Arthritis and Rheumatism, vol. 20, no. 3, pp. 190-200, 1990.

[47] K. W. Tan and Y. K. Tay, "A case of acute methotrexate toxicity," Annals of the Academy of Medicine Singapore, vol. 40, no. 2, pp. 97-99, 2011.

[48] J. I. Schwartz, N. G. B. Agrawal, P. H. Wong et al., "Examination of the effect of increasing doses of etoricoxib on oral methotrexate pharmacokinetics in patients with rheumatoid arthritis," Journal of Clinical Pharmacology, vol. 49, no. 10, pp. 1202-1209, 2009.

[49] H. Honjo, Y. Uwai, and K. Iwamoto, "Inhibitory effect of selective cyclooxygenase-2 inhibitor etoricoxib on human organic anion transporter 3 (hOAT3)," Drug Metabolism Letters, vol. 5, no. 2, pp. 140-137, 2011.

[50] A. Karim, D. S. Tolbert, T. L. Hunt, R. C. Hubbard, K. M. Harper, and G. S. Geis, "Celecoxib, a specific COX-2 inhibitor, has no significant effect on methotrexate pharmacokinetics in patients with rheumatoid arthritis," Journal of Rheumatology, vol. 26, no. 12, pp. 2539-2543, 1999.
[51] S. N. Hartmann, C. M. Rordorf, S. Milosavljev et al., "Lumiracoxib does not affect methotrexate pharmacokinetics in rheumatoid arthritis patients," Annals of Pharmacotherapy, vol. 38, no. 10, pp. 1582-1587, 2004.

[52] C. Palleria, A. Di Paolo, C. Giofrè et al., "Pharmacokinetic drugdrug interaction and their implication in clinical management," Journal of Research in Medical Sciences, 2013.

[53] A. N. Colebatch, J. L. Marks, D. M. van der Heijde, and C. J. Edwards, "Safety of nonsteroidal antiinflammatory drugs and/or paracetamol in people receiving methotrexate for inflammatory arthritis: a Cochrane systematic review," Journal of Rheumatology. Supplement, vol. 90, pp. 62-73, 2012.

[54] Arava (Leflunomide), Sanofi-Aventis. UK Summary of product characteristics, September 2009.

[55] EMEA, "EMEA public statement on leflunomide (Arava) severe and serious hepatic reactions," London, UK, March 2001, http://www.emea.europa.eu/docs/en_GB/document_library/ Public_statement/2009/12/WC500018389.pdf.

[56] R. L. Hill, D. J. Topliss, and P. M. Purcell, "Pancytopenia associated with leflunomide and methotrexate," Annals of Pharmacotherapy, vol. 37, no. 1, p. 149, 2003.

[57] J. McEwen, P. M. Purcell, R. L. Hill, L. J. Calcino, and C. G. Riley, "The incidence of pancytopenia in patients taking leflunomide alone or with methotrexate," Pharmacoepidemiology and Drug Safety, vol. 16, no. 1, pp. 65-73, 2007.

[58] J. Chan, D. C. Sanders, L. Du, and P. I. Pillans, "Leflunomideassociated pancytopenia with or without methotrexate," Annals of Pharmacotherapy, vol. 38, no. 7-8, pp. 1206-1211, 2004.

[59] J. Londono, A. M. Santos, P. I. Santos, M. F. Cubidez, C. Guzman, and R. Valle-Oñate, "Therapeutic efficacy and safety of methotrexate + leflunomide in Colombian patients with active rheumatoid arthritis refractory to conventional treatment," Revista Brasileira de Reumatologia, vol. 52, no. 6, pp. 837-845, 2012.

[60] S. W. Lee, H. J. Park, B. K. Kim et al., "Leflunomide increases the risk of silent liver fibrosis in patients with rheumatoid arthritis receiving methotrexate," Arthritis Research \& Therapy, vol. 14, no. 5, p. R232, 2012.

[61] W. Katchamart, J. Trudeau, V. Phumethum, and C. Bombardier, "Efficacy and toxicity of methotrexate (MTX) monotherapy versus MTX combination therapy with non-biological diseasemodifying antirheumatic drugs in rheumatoid arthritis: a systematic review and meta-analysis," Annals of the Rheumatic Diseases, vol. 68, no. 7, pp. 1105-1112, 2009.

[62] R. Elsby, L. Fox, D. Stresser et al., "In vitro risk assessment of AZD9056 perpetrating a transporter-mediated drug-drug interaction with methotrexate," European Journal of Pharmaceutical Sciences, vol. 43, no. 1-2, pp. 41-49, 2011.

[63] A. H. Gerards, R. B. M. Landewé, A. P. A. Prins et al., "Cyclosporin A monotherapy versus cyclosporin A and methotrexate combination therapy in patients with early rheumatoid arthritis: a double blind randomised placebo controlled trial," Annals of the Rheumatic Diseases, vol. 62, no. 4, pp. 291-296, 2003.

[64] P. Sarzi-Puttini, E. D’Ingianna, M. Fumagalli et al., "An open, randomized comparison study of cyclosporine A, cyclosporine $\mathrm{A}+$ methotrexate and cyclosporine $\mathrm{A}+$ hydroxychloroquine in the treatment of early severe rheumatoid arthritis," Rheumatology International, vol. 25, no. 1, pp. 15-22, 2005.

[65] L. Fuksa, E. Brcakova, G. Kolouchova et al., "Dexamethasone reduces methotrexate biliary elimination and potentiates its hepatotoxicity in rats," Toxicology, vol. 267, no. 1-3, pp. 165-171, 2010. 
[66] J. E. A. Wolff, H. Hauch, J. Kühl, R. M. Egeler, and H. Jürgens, "Dexamethasone increases hepatotoxicity of MTX in children with brain tumors," Anticancer Research, vol. 18, no. 4B, pp. 2895-2899, 1998

[67] O. A. Malysheva, M. Wahle, U. Wagner et al., "Low-dose prednisolone in rheumatoid arthritis: adverse effects of various disease modifying antirheumatic drugs," Journal of Rheumatology, vol. 35, no. 6, pp. 979-985, 2008.

[68] M. E. Weinblatt, J. M. Kremer, J. S. Coblyn et al., "Pharmacokinetics, safety, and efficacy of combination treatment with methotrexate and leflunomide in patients with active rheumatoid arthritis," Arthritis \& Rheumatism, vol. 42, pp. 1322-1328, 1999.

[69] P. Bird, H. Griffiths, K. Tymms et al., "The SMILE studysafety of methotrexate in combination with leflunomide in rheumatoid arthritis," The Journal of Rheumatology, vol. 40, no. 3, pp. 228-235, 2013.

[70] J. P. Callen, "Complications and adverse reactions in the use of newer biologic agents," Seminars in Cutaneous Medicine and Surgery, vol. 26, no. 1, pp. 6-14, 2007.

[71] B. T. Luong, B. S. Chong, and D. M. Lowder, "Treatment options for rheumatoid arthritis: celecoxib, leflunomide, etanercept, and infliximab," Annals of Pharmacotherapy, vol. 34, no. 6, pp. 743-760, 2000.

[72] H. Zhou, P. R. Mayer, J. Wajdula, and S. Fatenejad, "Unaltered etanercept pharmacokinetics with concurrent methotrexate in patients with rheumatoid arthritis," Journal of Clinical Pharmacology, vol. 44, no. 11, pp. 1235-1243, 2004.

[73] M. H. Weisman, L. W. Moreland, D. E. Furst et al., "Efficacy, pharmacokinetic, and safety assessment of adalimumab, a fully human anti-tumor necrosis factor-alpha monoclonal antibody, in adults with rheumatoid arthritis receiving concomitant methotrexate: a pilot study," Clinical Therapeutics, vol. 25, no. 6, pp. 1700-1721, 2003.

[74] RoActemra (Tocilizumab), Roche Registration Ltd. Summary of product characteristics, January 2009.

[75] Cimzia (Certolizumab pegol), UCB Inc. US Prescribing information, December 2008.

[76] Simponi (Golimumab), Centocor Ortho Biotech Inc. US Prescribing information, April 2009.

[77] J. Von Kempis, J. Dudler, P. Hasler et al., "Use of abatacept in rheumatoid arthritis," Swiss Medical Weekly, vol. 142, 2012.

[78] B. Dijkmans and A. Gerards, "Cyclosporin in rheumatoid arthritis: monitoring for adverse effects and clinically significant drug interactions," BioDrugs, vol. 10, no. 6, pp. 437-445, 1998.

[79] M. Baraldo, G. Ferraccioli, F. Pea, E. Gremese, and M. Furlanut, "Cyclosporine a pharmacokinetics in rheumatoid arthritis patients after 6 months of methotrexate therapy," Pharmacological Research, vol. 40, no. 6, pp. 483-486, 1999.

[80] R. B. Velagapudi, P. A. Noertersheuser, W. M. Awni et al., "Effect of methotrexate coadministration on the pharmacokinetics of adalimumab (Humira, Abbott) following a single intravenous injection," Arthritis \& Rheumatism, vol. 48, p. S141, 2003.

[81] Humira (Adalimumab), Abbott Laboratories. US Prescribing information, March 2009.

[82] B. Davies and T. Shaw, "Rituximab pharmacokinetic characteristics are not influenced by combination with methotrexate or cyclophosphamide," Annals of the Rheumatic Diseases, vol. 63, p. FRI0128, 2004.

[83] J. A. Singh, G. A. Wells, R. Christensen et al., "Adverse effects of biologics: a network meta-analysis and cochrane overview,"
Cochrane Database of Systematic Reviews, vol. 2, Article ID CD008794, 2011.

[84] A. E. Thompson and P. G. Bashook, "Rheumatologists' recommended patient information when prescribing methotrexate for rheumatoid arthritis," Clinical and Experimental Rheumatology, vol. 28, no. 4, pp. 539-545, 2010.

[85] E. N. van Roon, P. M. L. A. van den Bemt, T. L. T. A. Jansen, N. M. Houtman, M. A. F. J. van de Laar, and J. R. B. J. Brouwers, "An evidence-based assessment of the clinical significance of drugdrug interactions between disease-modifying antirheumatic drugs and non-antirheumatic drugs according to rheumatologists and pharmacists," Clinical Therapeutics, vol. 31, no. 8, pp. 1737-1746, 2009. 

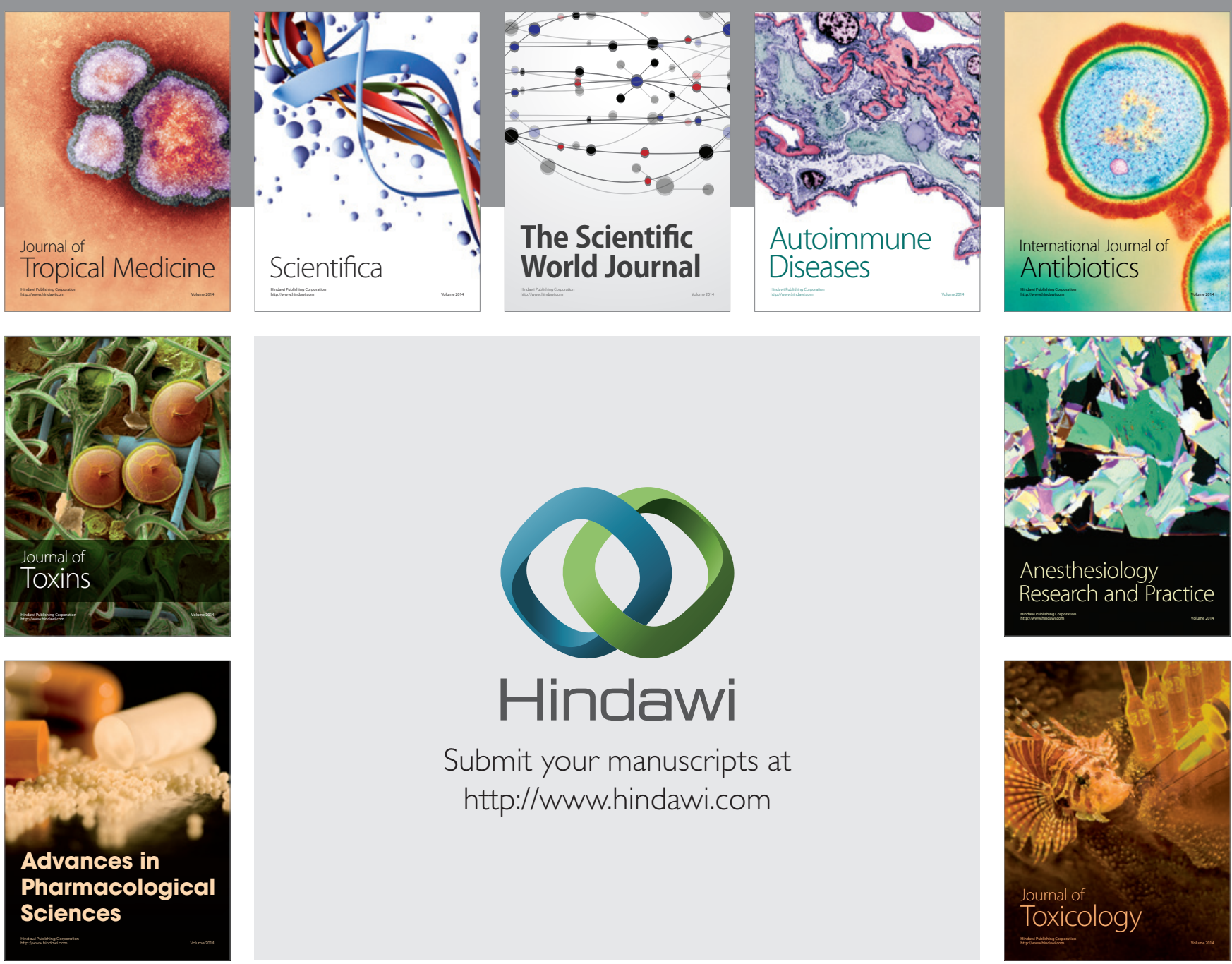

\section{Hindawi}

Submit your manuscripts at

http://www.hindawi.com
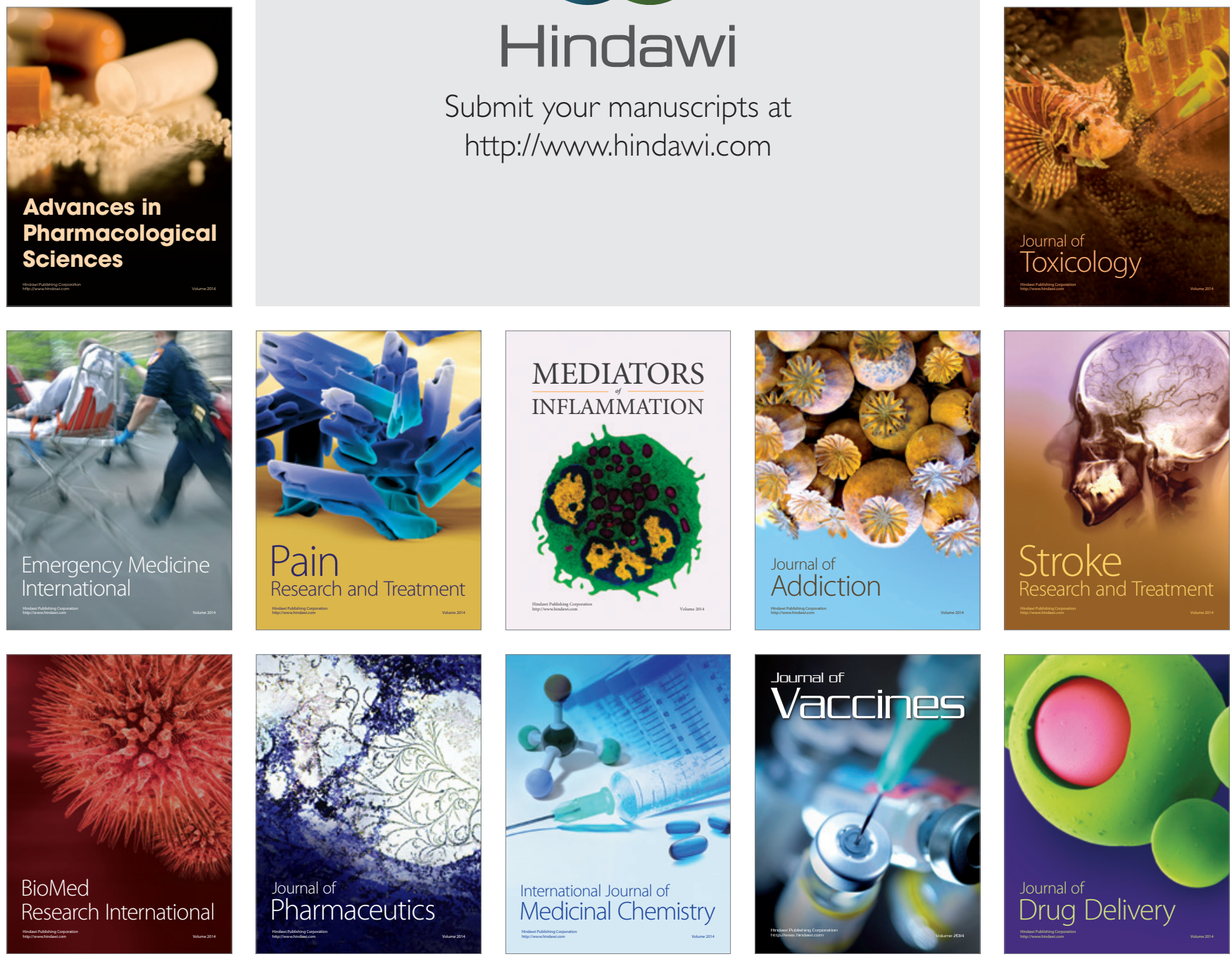